\title{
Microseismic activity analysis for the study of the rupture mechanisms in unstable rock masses
}

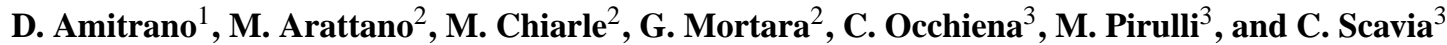 \\ ${ }^{1}$ LGIT, UMR5559, CNRS-Université Joseph Fourier, Grenoble, France \\ ${ }^{2}$ CNR-IRPI, Torino, Italy \\ ${ }^{3}$ Department of Structural and Geotechnical Engineering, Politecnico di Torino, Italy
}

Received: 30 October 2009 - Accepted: 1 February 2010 - Published: 15 April 2010

\begin{abstract}
Rockfalls are common instabilities in alpine areas and can cause significant damage. Since high mountains have been affected by an increasing number of these phenomena in the last years, a possible correlation with permafrost degradation induced by climate change has been hypothesized.

To investigate this topic, a monitoring system, made of 5 triaxial geophones and 1 thermometer, was installed in 2007 at the Carrel hut (3829 ma.s.l., Matterhorn, Northwestern Alps), in the frame of the Interreg IIIA Alcotra project n. 196 "Permadataroc".

The preliminary data processing relates to the classification of recorded signals, the identification of the significant microseismic events and the analysis of their distribution in time and space. The first results indicated a possible correlation between clusters of events and temperature trend, and a concentration of events in specific sectors of the rock mass.

Research is still in progress. The recording of data for a longer period is planned to fully understand seasonal trends and spatial distribution of microseismic activity, and possible relations with permafrost degradation. Nevertheless, the preliminary observations prove that the monitoring system can detect noises generated by rock slope deformation. Once fully developed, this technique could become a helpful tool for early warning and preliminary stability assessments.
\end{abstract}

\section{Introduction}

The progressive growth of socio-economic activities in alpine areas (e.g. tourism) has led to an increase in the risks related to natural hazards like rockfalls, landslides and debris flows (Jomelli et al., 2007). Recent climatic changes

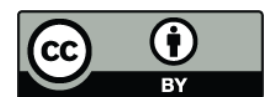

Correspondence to: $\mathrm{C}$. Occhiena (cristina.occhiena@polito.it) could also make the situation worse by increasing, in some cases, the frequency of these instabilities (Evans and Clague, 1994). As a result, researchers are becoming more and more interested in understanding possible correlations between slope instabilities and climate change (Collison et al., 2000; Jaedicke et al., 2008; Jakob and Lambert, 2009). Particular attention has been focused on the role played by permafrost degradation, and the consequent thawing of the ice filling the rock joints (Fischer et al., 2006; Gruber and Haeberli, 2007; Chiarle and Mortara, 2008; Huggel, 2009).

The awareness of alpine European countries of the problem was raised in summer 2003, when an exceptional heat wave hit central Europe and was accompanied by a large series of rockfall events along the entire alpine chain (Gruber et al., 2004). In consideration of the supranational character of climate warming and of related impacts, the Interreg III Alcotra project n. 196 "Permadataroc", which is one of the EU-funded programs for helping cross-border Europe's regions form partnerships to develop new solutions to economic, social and environmental challenges, was promoted. The project aimed to investigate possible correlations between permafrost degradation and increased rock slope instability in high altitude alpine areas, and to identify the most suitable investigation techniques to follow up slope evolution and related hazards.

Monitoring of rock instability and deformation in high elevation slopes was proposed as one of the activities of the project and the acoustic emission/microseismic (AE/MS) activity investigation technique was chosen: the variation of the stress state in a considered medium due to permafrost degradation and to the consequent initiation, formation, growth and coalescence of cracks, gives rise to elastic waves which can be detected using an AE/MS monitoring system.

Since the above technique is applied here to the scale of the site, the term microseismic activity is appropriate. Acoustic emission, concerning higher frequencies, is more suitable for the scale of the laboratory.

Published by Copernicus Publications on behalf of the European Geosciences Union. 
To understand the failure processes and to search for precursory patterns to failure, the AE/MS technique has been extensively used at laboratory rock sample scale (Lockner, 1993) and at an intermediate scale between the laboratory scale and the large tectonic earthquake for studies of seismicity and rockburst in mines or tunnels (Obert, 1977; Nicholson, 1992). Whereas, only a few applications exist at the slope scale and are mainly related either to open mines, quarries or volcano flanks (Hardy and Kimble, 1991; Kennedy and Niermeyer, 1971), with some rare exceptions concerning rocky cliff instabilities (Kolesnikov et al., 2003, Willenberg et al., 2004; Eberhardt et al., 2004; Amitrano et al., 2005) and mudslides (Amitrano et al., 2007; Dixon et al., 1996, 2003). In particular, Amitrano et al. (2005) have shown that microseismic monitoring is able to give interesting insights to gravitational instability and, in some cases, to provide failure precursory patterns useful for failure forecasting and hazard assessment. Moreover, an appropriate analysis of the microseismic activity can contribute in locating unstable areas.

While there are limits, due to the difficulties of processing and interpreting the recorded signals, and to the interference of environmental noises (e.g. traffic, animals, wind), the above technique has been considered the only one capable of giving helpful insight on the analysed processes, considering that rockfall events, at least at this stage, are usually small in size, but frequent and widespread on alpine slopes, and cannot be easily correlated in advance to specific rupture surfaces. Once tested, these techniques could be used as a tool for early warning when meteorological conditions change, which favour the initiation of rock slope instabilities.

With this purpose, a monitoring network, comprising of 5 geophones plus a thermometer, was installed in 2007 in the surrounding area of the J. A. Carrel hut (southwestern Matterhorn ridge, $3829 \mathrm{~m}$ a.s.l.). This paper aims to illustrate the characteristics of the study site, the technical details of the monitoring network and a first interpretation of recorded data. Technical problems and uncertainties in data processing and interpretation will be discussed. Future perspectives of the monitoring activity, along with its potential as a earlywarning tool, will be outlined.

\section{Characteristics of a microseismic monitoring system}

A typical microseismic monitoring system usually involves one or more transducers, an amplifying and filtering system and a recorder. However, it is known that the overall monitoring system necessary for each field project is "sitespecific"; this means that the consideration of the specific site conditions is involved in the selection of the most suitable transducers, installation technique and array geometry (Hardy, 2003).
When designing a field monitoring system, in fact, it must be realized that the mechanical signals associated with the microseismic activity are often of very low amplitude (e.g. $v=10^{-7} \mathrm{~m} / \mathrm{s}$ in some cases) and, thus, extremely high gain systems are required to convert these signals to useable electronic signal levels (normally 1-10 V) (Hardy, 2003).

The frequency content of the signal emitted by the fracture mechanism depends essentially on the source dimension. Considering a simple dislocation model as the source mechanism, it has been shown analytically that the spectrum is flat from low frequencies to the so-called corner frequency $f_{\mathrm{c}}=V_{\mathrm{r}} / s, V_{\mathrm{r}}$ being the Rayleigh wave velocity and $s$ being the source size. The smaller the source, the higher the corner frequency is. Above the corner frequency (i.e. $f>f_{\mathrm{c}}$ ), the spectrum amplitude decreases as $1 / f^{2}$. The signal energy is proportional to the elastic energy release at the source (Lockner, 1993; Evans, 1979), that is the product of the source size and the stress drop due to the failure mechanism. During the propagation of the emitted wave, the amplitude decreases due to both the geometrical expansion and the intrinsic attenuation of the material related to an-elastic behaviour of the material. The first term scales with the inverted squared distance of propagation, the second one depends on the material nature and on the typical size of its defects, that is the thickness of open fractures within a fractured rock mass. As a consequence, the intrinsic attenuation is higher for high frequencies which are generally no longer recordable after a given distance. In the case of fractures filled in by ice, this attenuation should by lower than for opened fractures.

The choice of the transducer type is, therefore, very important and it is necessary to keep in mind the later factors that may affect the frequency range of the recorded signals in situ.

The resonant frequency of the sensors influences the accuracy of the monitoring activity too; it is known that the micro-scale of the fracture at an early failure stage is evolving to macro-scale at the final stage and the duration of the fracture/cracking corresponding to those stages varies from microseconds to seconds. As the frequency component of elastic waves relates to the fracture scale, the resonant frequency of sensors should be determined corresponding to the scale of the rock mass fractures (Shiotani, 2006).

Another problem regarding the field studies, is the noise affecting the recorded signals, due to the environmental noises, such as wind, precipitation or human presence, expected in situ. The causes of the environmental noise should be assessed before the installation in order to characterise the noise frequency range in the signals. This is especially true in the case of long term rock monitoring, where manual filtering could be difficult for the large number of data to be processed.

There are two main classes of monitoring, depending on the aims of the study and the number of transducers involved, named "general monitoring" and "location monitoring". 

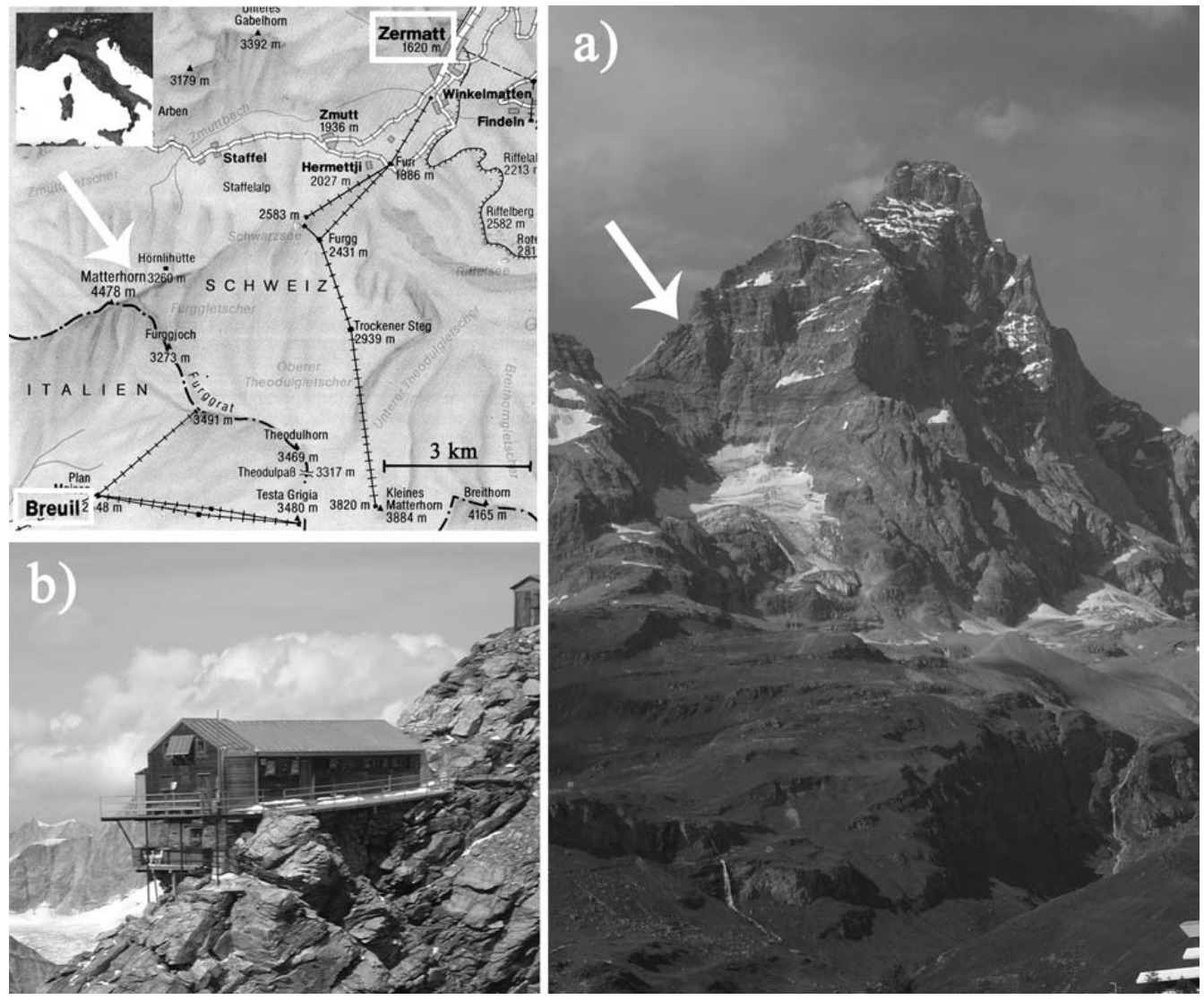

Fig. 1. Location of the study site (a) Matterhorn peak (image courtesy of Valle dAosta Region, Italy); (b) J. A. Carrel hut (image courtesy of Valle dAosta Region, Italy).

The aim of a general field monitoring system is to establish if microseismic activity is being generated in the area under investigation and if it is associated with various monitored field parameters. This monitoring usually involves only one transducer and cannot determine the actual source of the recorded events.

In many cases, it is necessary to locate the source of all recorded events to insure that only events falling inside the net are analysed. In this case, it must be considered that several location methods can be found in literature, but their use requires that the sensors have specific characteristics, or are in sufficient number and spatial distribution (Hardy, 2003). In particular, the number and type of sensors have to be chosen in accordance with the results that are required. A minimum of four uniaxial transducers are required for epicentre location (location in the horizontal plane), leaving the source depth undetermined, and a minimum of five uniaxial transducers is required for three dimensional or hypocentre location (Hardy, 2003). Single triaxial geophones can be used for locating sources applying the polarization technique (Kolesnikov et al., 2003).

\section{Example of application: the monitoring network of the J. A. Carrel hut}

A monitoring system was installed on the S-W flank of the Matterhorn Peak, close to the J. A. Carrel hut, at $3829 \mathrm{~m}$ a.s.l. in the context of the "Permadataroc" project.

The Matterhorn belongs to the Pennine Alps. With its 4478-m high summit, lying on the border between Switzerland and Italy, it is one of the highest peaks in the Alps. The mountain overlooks the town of Zermatt in the Canton of Valais (Switzerland) on the north and Breuil (Cervinia) in the Aosta Valley (Italy) to the south (Fig. 1).

The choice of this site was justified by the presence of the hut, which provides a unique logistic support, and because of the relevant number of rockfalls which took place in recent years in the area. Moreover, the consolidation works, carried out in 2004 and 2005 on the rock spur on which the hut is built, were the reason for drilling four boreholes to install the geophones (Fig. 4).

The most important rockfall event in the area was the "Cheminée" rockfall, occurred in August 2003 along the Italian climbing route to the Matterhorn, just below the Carrel hut (Fig. 2a). No one was injured but the way was precluded 


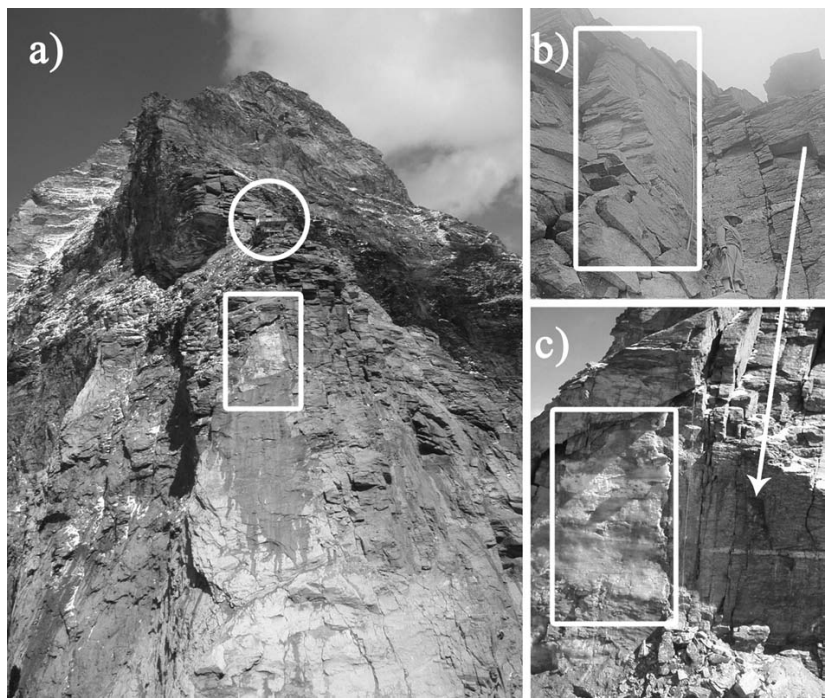

Fig. 2. Views of the Cheminée rockfall scar: (a) view from the bottom upwards: the Carrel hut is in the circle; the rockfall scar is in the square. Beneath the square, the water is clearly visible coming from joint ice melting (image courtesy of Valle d'Aosta Region, Italy); (b) historical image of the slope before the event (in the square the rock mass which detached on August 2003); (c) the area after the event: the square highlights the ice lens exposed after the detachment (images courtesy of L. Trucco).

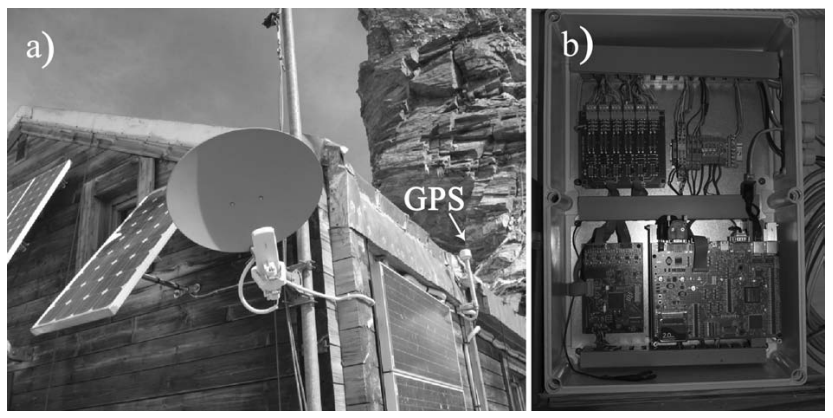

Fig. 3. (a) The parabolic aerial, the gps and the solar panels installed on the J. A. Carrel hut; (b) the acquisition system installed inside the hut (images modified after Signori and Bani, 2007).

to climbers for a long period. This event was of particular scientific interest since a large ice lens was observed on the detachment surface, calling for a possible role of permafrost degradation and, thus, climate warming, in the event initiation (Fig. 2c).

\subsection{Geological and morphological settings}

The Matterhorn (Monte Cervino, in Italian) is one of the most spectacular mountains in the world. It is a gigantic, sharp and isolated rock pyramid, with four faces facing the four
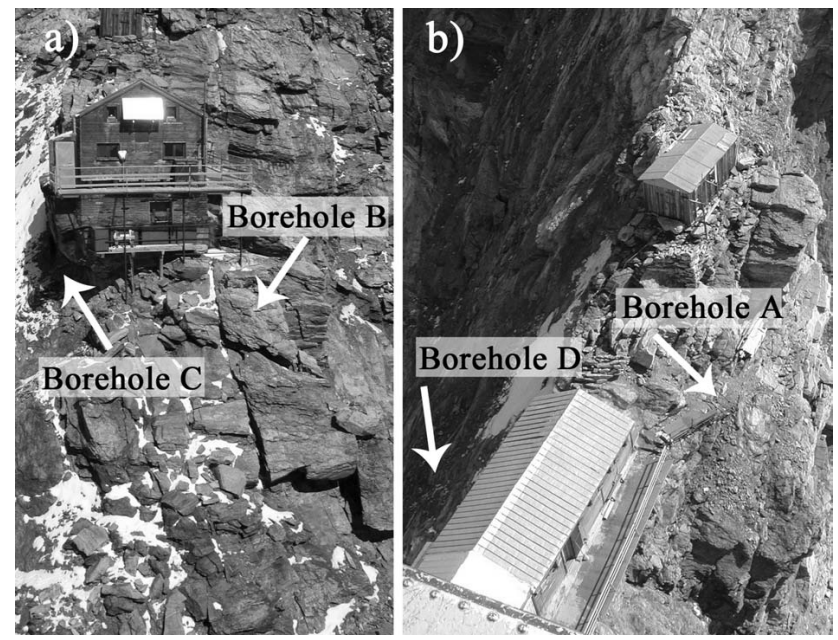

Fig. 4. Position of the boreholes with respect to the Carrel hut (images courtesy of Valle d'Aosta Region, Italy).

compass points. The Matterhorn faces are steep, so that only small patches of snow and ice cling to them; while, regular avalanches send the snow down to accumulate on the glaciers at the base of each face.

The Matterhorn is mainly composed of orthogneisses belonging to the Dent Blanche nappe (Arolla series), including massive metagranitoids, but also fine-grained gneisses and mylonites. The orthogneisses are underlined by a lens of metagabbros, outcropping on the western side of the massif from an elevation of about $3000 \mathrm{~m}$ up to about $3500 \mathrm{~m}$ a.s.l. The peak's summit, above $4200 \mathrm{~m}$ a.s.l., is carved in the kinzigites of the Valpelline series (micaschists and paragneisses, with intercalations of marbles and mafic rocks). The contacts of the orthogneisses with both metagabbros and kinzigites are mainly horizontal, underlined by mylonites.

Rock strength properties are affected by the ductile-brittle deformation history of the massif. In the orthogneisses, schistosity represents the main rock discontinuity. Its geometry is controlled by a large recumbent fold, whose hinge is located on the western side of the massif, and by related parasitic folds. Slope morphology and stability are also closely controlled by several joint sets. Considering the high elevation of the massif, ice filling in the joints is thought to greatly contribute to rock strengthening.

The Carrel hut, where the monitoring network was installed, is located on a narrow terrace along the south-western Matterhorn ridge, at the base of a characteristic rock spur known as "Gran Torre". In this sector, slopes are carved in highly fractured orthogneisses. The presence of ice infilling in the rock joints has been proven by ice outcropping in a block fall scar which developed just above the Carrel hut, and by ice filling in some of the drilled boreholes. 


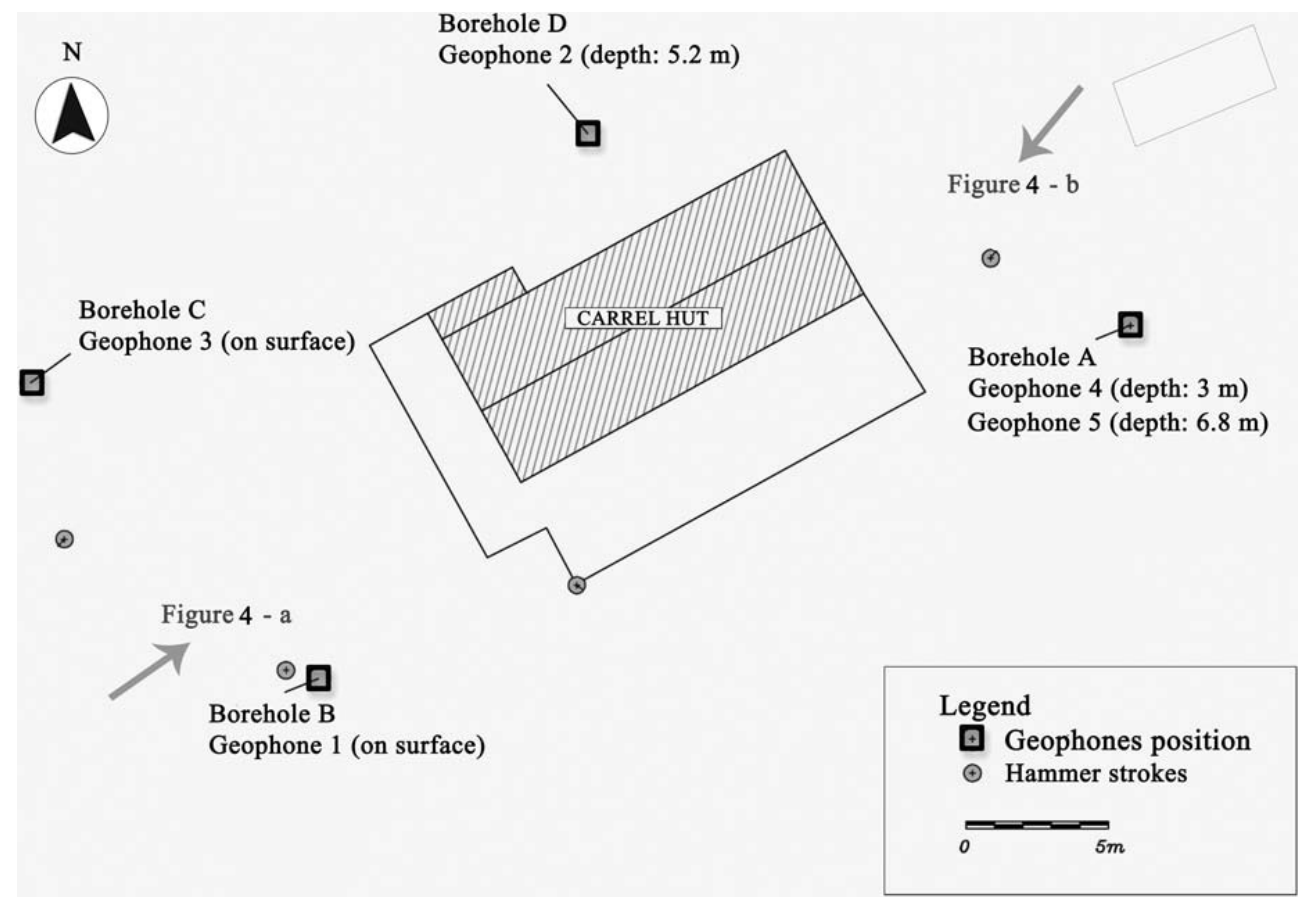

Fig. 5. The J. A. Carrel hut and the position of the geophones and of the points corresponding to the hammer strokes (images modified after Signori and Bani, 2007).

\subsection{Description of the monitoring system}

The monitoring system installed at the Carrel hut is made of an 18-channel acquisition system, which is placed inside the hut (at present, only 15 of the 18 channels are used and are acquired simultaneously), five triaxial transducers for boreholes, a gps receiver, a power supply group connected to solar panels. The system is completed by a wireless data transmission system, made of a parabolic aerial connecting the station inside the hut to the village of Breuil (Cervinia), where data are periodically downloaded, and by a thermometer that records the air temperature in the hut every $30 \mathrm{~min}$ (Fig. 3).

The type, number and position of the transducers were selected considering:

- the high degree of fracturation characterising the rock mass on which the Carrel hut is built (Sect. 3.1);

- the purpose of locating the sources of microseismic signals occurring around the hut.

Five Mark Products L-40-A2 watertight triaxial geophones with a natural frequency of $100 \mathrm{~Hz}$ were then chosen.

The acquisition system, installed inside the hut, is powered by a direct voltage from 10.5 to $18 \mathrm{~V}$, consumes $3 \mathrm{~W}$ every 6 channels. Its characteristics are summarized in Table 1.

When the installation of the geophones took place (September 2007), two of the four boreholes (B and C in Fig. 4) were not traceable since they were buried by snow
Table 1. Details of the acquisition system installed inside the hut.

\begin{tabular}{lc}
\hline Sampling frequency & $8 \mathrm{kHz}$ \\
Gain of the amplifiers & $38 \mathrm{~dB}$ \\
Vertical dynamics (number of sampling & \\
points between the minimum & \\
and the maximum amplitude) & $16 \mathrm{bits}$ \\
Minimum and maximum amplitude & $\pm 3 \mathrm{~V}$ \\
Mean value of noise & $0.002 \mathrm{~mm} / \mathrm{s}$
\end{tabular}

and debris. As a consequence, two geophones were installed on the surface (geophones 1 and 3 in Fig. 5), one geophone was put at a depth of $5.2 \mathrm{~m}$ in borehole D (geophone 2 in Fig. 5) and two geophones were positioned at a depth of $3 \mathrm{~m}$ and $6.8 \mathrm{~m}$, respectively, in borehole $\mathrm{A}$ (geophones 4 and 5 in Fig. 5).

Rockfall events in high mountains, characterised by the presence of alpine permafrost, mainly originate in the active layer. The active layer (i.e. the upper layer of permafrost that thaws during the hot season and freezes again during the autumn) is characterised by a variable depth during the year. Since the presence of alpine permafrost is assessed on the top of the Matterhorn with an active layer ranging between $0 \dot{m}$ and $7 \mathrm{~m}$ (e.g. Gruber and Haeberli, 2007), the sensor depth was planned with the aim of investigating the presence of 
rupture mechanisms in the active layer and the relationship between the active layer development and the temperatures trend.

The bottom of the deep-geophones was resinated before the installation in the boreholes. After their placement, the connection between each geophone and the surrounding rock was guaranteed by adding and compacting sand. Finally, the electric cables coming out from the boreholes were sheathed or buried to protect them from damages.

Once the installation was completed, the system was tested by hammering some georeference points and checking the type of signal recorded by the net. Furthermore, the source time of each hammer stroke was stored to allow the subsequent re-location of the recorded signal source (using the arrival time at each geophone), gathering, in this way, the additional information about the characteristics of the medium in which the system is installed.

\section{Data recording}

Recorded data are stored on a CompactFlash card with standard formatting and can be downloaded from the post in Breuil (Cervinia) using the wireless, computer-based data transmission system. This system allows bypassing the inaccessibility of the site under adverse meteorological conditions.

Since the recording of an event occurs when a threshold value (triggering condition) is exceeded by a selected number of channels, a calibration period was necessary after the installation to correctly set this value. The threshold allows insignificant events to be ignored and, at the same time, not to neglect significant events. A threshold value equal to $0.01 \mathrm{~mm} / \mathrm{s}$, to be exceeded on at least six channels, was finally fixed.

Each time that the threshold is exceeded, the recording lasts for $1.5 \mathrm{~s}$ : $0.5 \mathrm{~s}$ before the triggering point (pretrigger) and $1 \mathrm{~s}$ after the triggering point (postrigger).

\section{Data processing}

In this section, the set of data (627 events) recorded from 1 November 2007 (i.e. when the triggering condition was set equal to $0.01 \mathrm{~mm} / \mathrm{s}$ ) to 7 April 2008 is analysed.

After the characterisation and classification of recorded signals, the possible correlation between the number of events and temperature trends was investigated.

\subsection{Classification of the recorded events}

To test the quality of the monitoring network, a screening of recorded data had been initially planned. This procedure was devoted to identify which geophones usually pick up the signal in a good way and which ones have a bad quality recording. To this aim, a classification based on the amplitude of the recorded signals has been provided and information obtained from the analysed dataset has been summarized in a table represented in Fig. 6. For each recorded event, a line of the table has been filled as follows:

- From the comparison of the signals recorded by the geophones of the network: the cells $\left[\operatorname{Deg}_{i}\right]_{i=\text { number of the geophone of the five geophones }}$ have been filled with a mark ranging from 1 (low amplitude) to 5 (high amplitude), being 5 the geophones, to identify which geophone has recorded the considered event with a higher amplitude.

- From the comparison of the signals recorded by the three channels of a geophone: the cells $\left[\mathrm{CH}_{i j}\right]_{j=x, y, z}$ of the geophone have been filled with a mark ranging from 1 (low amplitude) to 3 (high amplitude), being 3 the channels, to identify which channel has recorded the considered event with a higher amplitude.

- The cell $[\downarrow \uparrow]$ of each geophone has been filled with a value equal to 1 to indicate the polarization of the first peak value for the vertical channel (z-axis).

All the analysed signals were recorded during the cold season (i.e., 6 November-7 April). The adverse climate conditions, characterising the above period, make it impossible for climbers to reach the hut and consequently no noise of this type is included in the recorded traces.

The observation of the classed signals have confirmed the presence of two main categories of events (Fig. 7):

a) events characterised by signals with high amplitude on all the channels (e.g. Fig. 7a);

b) events characterised by signals with high amplitude only on some channels (e.g. Fig. 7b).

For some events of category b) the high amplitude concerns only superficial channels (e.g. Fig. 7b). This aspect can indicate a possible local impact on a geophone and, for this reason, these signals are considered not significant in relation to rock stability.

Furthermore, within both the a) and b) categories, the presence of some multiple events was assessed (i.e. more than one event exists in the same recording) (Fig. 8). Different hypotheses have been advanced on the meaning of these multiple events as a function of some dissimilar characteristics of the traces: a short succession of cracking events (e.g. Fig. 8a) or a sequence of falling blocks (e.g. Fig. 8b).

As far as the information obtained by the classification is concerned, it mainly emerges that:

1. Out of a total of 627 events, 359 were picked up with a higher amplitude by superficial channels and 256 with a higher amplitude by deep channels, while 12 events were picked up with almost the same amplitude both on superficial and deep channels; 


\begin{tabular}{|c|c|c|c|c|c|c|c|c|c|c|c|c|c|c|c|c|c|c|c|c|c|c|c|c|}
\hline \multicolumn{5}{|c|}{ Geophone 1- on surface } & \multicolumn{5}{|c|}{ Geophone $2-5.2 \mathrm{~m}$} & \multicolumn{5}{|c|}{ Geophone 3-on surface } & \multicolumn{5}{|c|}{ Geophone $4-3 m$} & \multicolumn{5}{|c|}{ Geophone $5-6.8 \mathrm{~m}$} \\
\hline $\operatorname{Deg}_{1}$ & $\mathrm{CH}_{12}$ & $\mathrm{CH}_{1}$ & $\mathrm{CH}_{1}$ & $\downarrow \uparrow$ & $\operatorname{Deg}_{2}$ & $\mathrm{CH}_{2}$ & $\mathrm{CH}_{2}$ & $\mathrm{CH}_{2 z}$ & $\downarrow \uparrow$ & $\operatorname{Deg}_{3}$ & $\mathrm{CH}_{3 \mathrm{x}}$ & $\mathrm{CH}_{3 \mathrm{y}}$ & $\mathrm{CH}_{3}$ & $\geq \downarrow 1$ & $\operatorname{Deg}_{4}$ & $\mathrm{CH}_{4 x}$ & ${ }_{\mathrm{x}} \mathrm{CH}_{4 \mathrm{y}}$ & $\mathrm{CH}_{4 z}$ & $=\downarrow 1$ & Degs & $\mathrm{CH}_{5 \mathrm{x}}$ & $\mathrm{CH}_{5}$ & $\mathrm{CH}_{5 z}$ & $\downarrow \downarrow \uparrow$ \\
\hline 3 & 3 & 3 & 3 & $\begin{array}{lll}01 & 1\end{array}$ & 5 & 3 & 3 & 3 & $\begin{array}{lll}10 & \end{array}$ & 4 & 1 & 3 & 2 & $\begin{array}{lll}0 & 1\end{array}$ & 2 & 2 & 3 & 2 & $\begin{array}{ll}0 & 1\end{array}$ & 2 & 1 & 3 & 1 & $\begin{array}{ll}01 \\
\end{array}$ \\
\hline 3 & 3 & 3 & 3 & $\begin{array}{lll}0 & 1\end{array}$ & 5 & 3 & 3 & 3 & $\begin{array}{lll}1 & 0\end{array}$ & 4 & 3 & 3 & 2 & $\begin{array}{lll}0 & 1\end{array}$ & 3 & 2 & 3 & 3 & 10 & 4 & 2 & 3 & 2 & $\begin{array}{lll}0 & 1\end{array}$ \\
\hline 3 & 3 & 3 & 3 & $\begin{array}{ll}0 & 1\end{array}$ & 5 & 3 & 2 & 3 & $\begin{array}{ll}0 & 1\end{array}$ & 3 & 2 & 3 & 2 & 10 & 4 & 3 & 3 & 3 & $\begin{array}{lll}0 & 1\end{array}$ & 4 & 3 & 3 & 3 & $\begin{array}{ll}0 & 1 \\
0\end{array}$ \\
\hline
\end{tabular}

Fig. 6. Structure of the event analysis table: each line corresponds to one event. "Deg $i$ ": the amplitude of the signal observed on the geophone compared to the other geophones; " $\mathrm{CH}_{i j}$ ": the amplitude of the signal observed on each channel of one geophone; " $\downarrow$ ": the direction of the first peak value for the z-axis.

2. geophone 2 did not pick just 2 events up. In sequence, geophones number $3,1,4$, and 5 follow;

3. geophone 2 detected the largest number of events and with the highest amplitude. In sequence geophones number $3,1,4$, and 5 follow.

Observation 3) supports the hypothesis that many of the event sources could be located on the western side of the hut.

\subsection{Correlation between events and temperature}

The air temperature recorded inside the hut has been used to investigate possible relations between slope deformation and seasonal temperature variations. To this aim, a complete year-round dataset would be needed, but first some considerations can be done: also analysing the six month dataset presently available.

The superposition of the number of events per day on the daily temperature trend (Fig. 9) shows that many events are in a few specific days:

- 9 November 2007, 113 events;

- 4 March 2008, 76 events;

- 5 March 2008, 59 events;

- 20 March 2008, 77 events.

As previously mentioned, the adverse climate conditions characterising the analysed recording period make it impossible for people to reach the hut and consequently no witnesses to the rockfall events are available.

Since the first accumulation of events fall at the beginning of the analysed time interval, the temperature recorded during the calibration of the system (1-31 October 2007) was also added to the graph for viewing the temperature trend in a wider range of time.

The presence of temporal gaps in both the temperature and recorded events are attributable to the filling of the CompactFlash memory (when referring to the calibration period of the system) or to the low-power of the system caused by bad weather conditions. But the interpretation of the data is not prevented.
Scanning the available information, it can be noticed that the observed increase in the number of daily events always takes place on occasions of abrupt temperature falls. In fact:

- the 113 events of 9 November were recorded when the temperature dropped from $+2.19^{\circ} \mathrm{C}$ on 5 November to $-12.42^{\circ} \mathrm{C}$ on 10 November;

- the 76 and 59 events of 4 and 5 March, respectively, were recorded when the temperature dropped from $2.63^{\circ} \mathrm{C}$ on 25 February to $-10.4^{\circ} \mathrm{C}$ on $4-5$ March;

- the 77 events of 20 March were recorded when the temperature dropped from $-6.56^{\circ} \mathrm{C}$ on 16 March to $12.10^{\circ} \mathrm{C}$ on 21 March.

These observations are in agreement with information on the mechanisms through which climate can control slope stability, available in literature (e.g. Gruner, 2008).

\section{Conclusions and further developments}

This paper presents the first results obtained with the microseismic monitoring system installed on the Matterhorn, in the frame of the Interreg IIIA Alcotra "Permadataroc" project, to investigate the relations between rock slope instability and climate, under global warming scenarios.

Many technical problems, which can be ascribed mainly to the extreme operational conditions (extreme weather conditions and difficult access to the site), only allowed the correct functioning of the monitoring network for only a 6-months period (November 2007-April 2008), thus, limiting data collection to one winter season. Recording and interpretation of events and temperatures for a longer period is needed to better understand spatial and temporal distribution of events.

Nevertheless, recorded data allow some preliminary considerations: 1) many of the sources could gather in the western side of the hut; and 2) event concentrations occur when the temperature rapidly falls. These observations prove that the installed monitoring network is able to detect noises generated by rock slope deformation and can, thus, be a helpful tool to investigate rock response to climate forcing, as well as to detect unstable rock masses. Once fully developed 


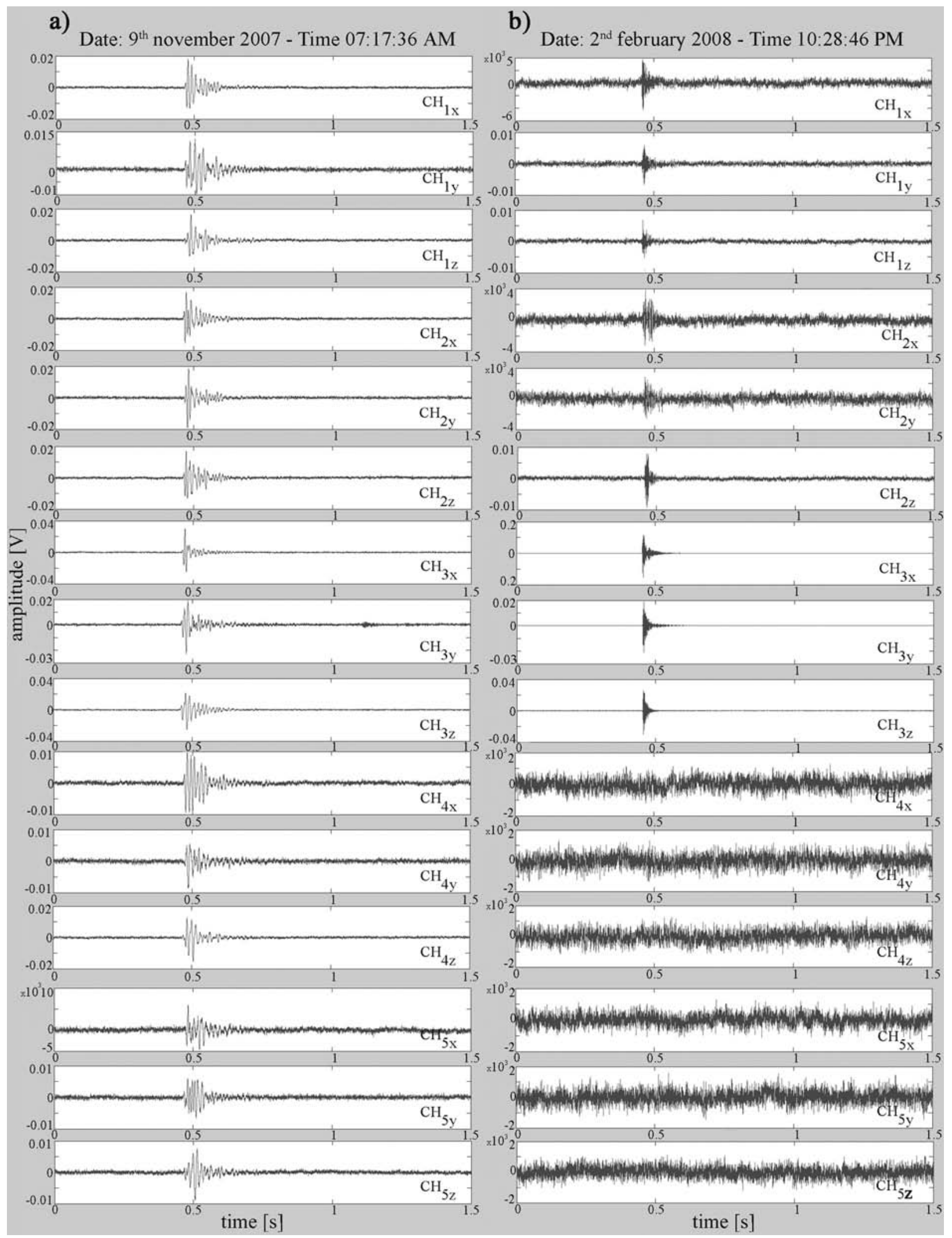

Fig. 7. Examples of recorded events: (a) event recorded with a high amplitude on all the channels; (b) event recorded with a high amplitude on only some channels. 


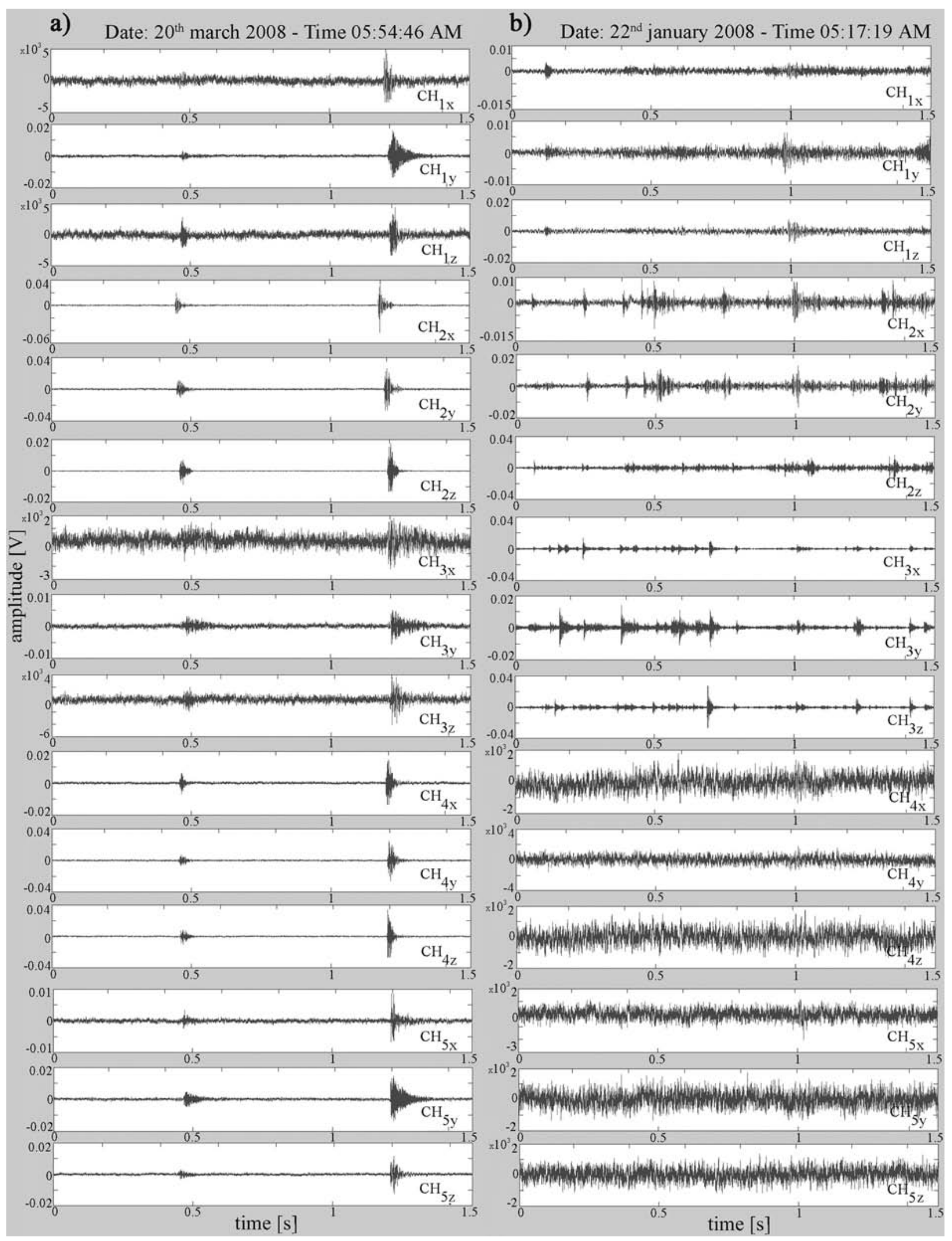

Fig. 8. Examples of recorded multiple events: (a) short succession of cracking events; (b) sequence of falling blocks. 


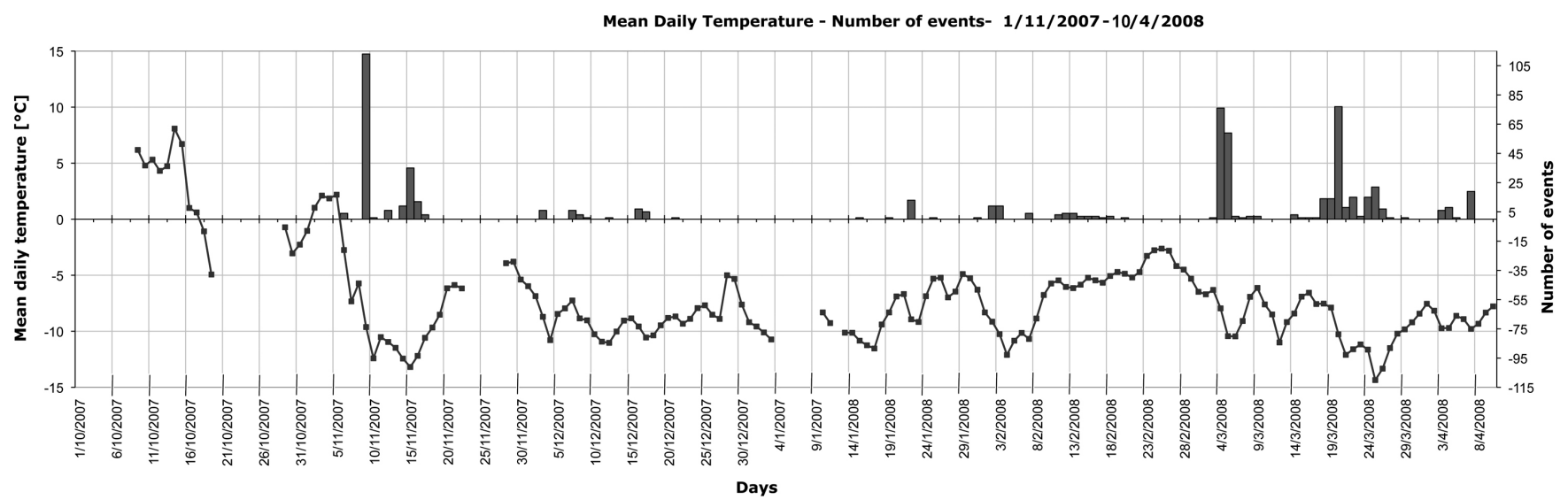

Fig. 9. Graph of the total number of events per day and the daily temperature trend: continuous line represents daily temperature trend; histogram represents daily number of events.

and tested, this technique could become a helpful tool for advance warning when meteorological conditions set up, which favour the initiation of rock slope instabilities. Moreover, in complex geostructural settings, as the one analysed here, this technique could help focus on rock slope portions needing detailed stability assessment investigations.

Further developments of the work will include; 1) development of a 3-D wave velocity model and consequently a sonic tomography of the investigated area, to allow a better location of the sources of the events, and 2) the enlargement of the monitored area, by adding new geophones to the net.

Acknowledgements. The described activity has been developed in the frame of the Interreg IIIA Alcotra project n. 196 "Permadataroc", coordinated by Fondazione Montagna Sicura. The authors wish to thank the Valle d'Aosta Regional Administration (Direzione Tutela del Territorio, Assessorato Territorio, Ambiente e Opere Pubbliche) for the logistic and financial support, Solgeo S.r.l. who assembled and installed the monitoring network, the Cervinia alpine guides for their assistance during all the work phases; Franco Godone, Marco Baldo and Daniele Giordan of the CNR-IRPI, for the technical assistance, in particular during the topographic surveys at the Carrel hut; Marco Succio for the support given during the installation of the monitoring network and during the initial phases of the monitoring activity.

Edited by: P. Allasia

Reviewed by: P. Dight and another anonymous referee

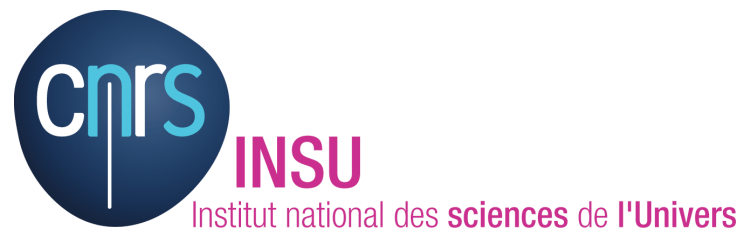

The publication of this article is financed by CNRS-INSU.

\section{References}

Amitrano, D., Grasso, J. R., and Senfaute, G.: Seismic precursory patterns before a cliff collapse and critical-point phenomena, Geoph. Res. Let., 32(8), L08314, doi:10.1029/2004GL022270, 2005.

Amitrano, D., Gaffet, S., Malet, J.-P., and Maquaire, O.: Understanding mudslides through micro-seismic monitoring: The Super-Sauze (South French Alps) case study, B. Soc. Geol. Fr., 178(2), 149-157; doi:10.2113/gssgfbull.178.2.149, 2007.

Chiarle, M. and Mortara, G.: Geomorphological impact of climate change on alpine glacial and periglacial areas. Examples of processes and description of research needs, in: Proceedings 11th Interpraevent Congress 2008 "Protection of populated territories from floods, debris flows, mass movements and avalanches", Dornbirn, Austria, 2, 111-122, 26-30 Mai 2008.

Collison, A., Wade, S., Griffiths, J., and Dehn, M.: Modelling the impact of predicted climate change on landslide frequency and magnitude in SE England, Eng. Geol., 55(3), 205-218, 2000.

Dixon, N., Hill, R., and Kavanagh, J.: Acoustic emission monitoring of slope instability: development of an active waveguide system, Geotechnical Engineering, 156(2), 83-95, 2003.

Dixon, N., Kavanagh, J., and Hill, R.: Monitoring landslide activity and hazard by acoustic emssion, J. Geol. Soc. China, 39(4), 437464, 1996.

Eberhardt, E., Spillmann, T., Maurer, H., Willenberg, H., Loew, S., and Stead, D.: The Randa Rockslide Laboratory: Establishing brittle and ductile instability mechanisms using numerical modelling and microseismicity, Proceedings of the 9th International Symposium of Landslides, Rio de Janeiro, Brazil, 481487, 2004.

Evans, A. G.: Acoustic emission sources in brittle solids, in: Fundamentals of acoustic emission, edited by: Ono, K., University of California, Los Angeles, 209-227, 1979.

Evans, S. G. and Clague, J. J.: Recent climatic change and catastrophic geomorphic processes in mountain environments, Geomorphology, 10, 107-12, 1994.

Fischer L., Kääb A., Huggel C. and Noetzli J.: Geology, glacier retreat and permafrost degradation as controlling factors of slope 
instabilities in a high-mountain rock wall: the Monte Rosa east face, Nat. Hazards Earth Syst. Sci., 6, 761-772, 2006, http://www.nat-hazards-earth-syst-sci.net/6/761/2006/.

Gruber, S., Hoelzle, M., and Haeberli, W.: Permafrost thaw and destabilization of Alpine rock walls in the hot summer of 2003, Geophys. Res. Lett., 31, L13504, doi:10.1029/2004GL020051, 2004.

Gruber, S. and Haeberly, W.: Permafrost in steep bedrock slopes and its temperature related destabilization following climate change, J. Geophys. Res., 112, F02S18, doi: 10.1029/2006JF000547, 2007

Gruner, U.: Climatic and meteorological influences on rockfall and rockslides, in: Proceedings 11th Interpraevent Congress 2008 "Protection of populated territories from floods, debris flows, mass movements and avalanches“, Dornbirn, Austria, 2, 147158, 26-30 Mai 2008.

Hardy, H. R. and Kimble, E. J.: Application of high-frequency AE/MS techniques to rock slope monitoring, in: Proceedings Fifth Conference on Acoustic Emission/Microseismic Activity in Geologic Structures and Materials, Pennsylvania State University, Trans Tech Publications, Clausthal, Germany, 1991

Hardy, H. R.: Acoustic emission/microseismic activity - Principles, Techniques and Geotechnical Applications, A.A. Balkema, Lisse, Netherlands, 2003.

Huggel, C.: Recent extreme slope failures in glacial environments: effects of thermal perturbation. Quaternary Sci. Rev., 28(11-12), 1119-1130, 2009.

Jaedicke, C., Solheim, A., Blikra, L. H., Stalsberg, K., Sorteberg, A., Aaheim, A., Kronholm, K., Vikhamar-Schuler, D., Isaksen, K., Sletten, K., Kristensen, K., Barstad, I., Melchiorre, C., Høydal, Ø. A., and Mestl, H.: Spatial and temporal variations of Norwegian geohazards in a changing climate, the GeoExtreme Project, Nat. Hazards Earth Syst. Sci., 8, 893-904, 2008, http://www.nat-hazards-earth-syst-sci.net/8/893/2008/.

Jakob, M. and Lambert, S.: Climate change effects on landslides along the southwest coast of British Columbia, Geomorphology, 107, 275-284, doi:10.1016/j.geomorph.2008.12.009, 2009.
Jomelli, V., Brunstein, D., Grancher, D., and Pech, P.: Is the response of hill slope debris flows to recent climate change univocal? A case study in the Massif des Ecrins (French Alps), Climatic Change, 85, 119-137, doi:10.1007/s10584-006-92090, 2007.

Kennedy, B. A. and Niermeyer, K. E.: Slope Monitoring systems used in the Prediction of a Major Slope Failure at the Chuquicamata Mine, Chile, in: Proc. On Planning Open Pit Mines, Balkema, Johannesburg, South Africa, 1971.

Kolesnikov, Yu. I., Nemirovich-Danchenko, M. M., Goldin, S. V., and Seleznev, V. S.: Slope stability monitoring from microseismic field using polarization methodology, Nat. Hazards Earth Syst. Sci., 3, 515-521, 2003, http://www.nat-hazards-earth-syst-sci.net/3/515/2003/.

Lockner, D. A.: The role of acoustic emission in the study of rock fracture, Int. J. Rock Mech. Min., 30(7), 883-899, 1993.

Nicholson, C.: Recent developments in rockburst and mine seismicity research, in: Rock Mechanics, edited by: Wawersik, T. A., Balkema, Rotterdam, Holland, 1992.

Obert, L.: The Microseismic Method: Discovery and Early History, in: Proceeding First Conference on Acoustic Emission/Microseismic Activity in Geologic Structures and Materials, The Pennsylvania State University, Trans Tech Publications, Clausthal, Germany, 1977.

Shiotani, T.: Evaluation of long-term stability for rock slope by means of acoustic emission technique, NDT \& Int., 39, 217-228, 2006.

Signori, M. and Bani, D.: Cervino - Capanna Carrel. Impianto di monitoraggio per emissioni acustiche, Solgeo s.r.l. Internal Report, Rel. G0304_07, 2007

Willenberg, H., Evans, K. F., Eberhardt, E., Loew, S., Spillmann, T., and Maurer, H.: Geological, geophysical and geotechnical investigations into the internal structure and kinematics of an unstable sliding mass in crystalline rock, Proceedings of the 9th International Symposium of Landslides, Rio de Janeiro, Brazil, 489-494, 2004. 